\title{
Forças de transformação do ecossistema amazônico
}

\author{
ANTONIA M. M. FERREIRA e ENÉAS SALATI
}

\section{Introdução}

A

O REFERIRMO-NOS à Amazônia, uma série de imagens nos vem à mente e, a cada uma delas, corresponde uma definição sobre o que seja essa região. Foi considerada como o domínio da grande floresta tropical exuberante, intrincada, inúmeras vezes referida na literatura como o "Inferno Verde" e/ ou "Floresta Amazônica", como uma das maiores bacias hidrográficas do mundo - Solimões-Amazonas - e/ ou como uma vasta planície fluvial formada, predominantemente, por terrenos baixos, muitas vezes denominada de "Vale Amazônico".

Mais recentemente foi, ainda, definida como a maior reserva de biodiversidade do planeta e uma das maiores em recursos minerais. Por vezes é lembrada como uma região onde ainda ocorrem remanescentes de grupos humanos autóctones, com culturas e histórias próprias, anteriores ao descobrimento destas terras. Fala-se, ainda, de uma Amazônia (brasileira) com 60\% de sua população habitando cidades e/ ou aglomerações urbanas. De outro, é a Amazônia legal.

Fisionomicamente, o domínio amazônico associa-se às bacias hidrográficas do Solimões-Amazonas, do Tocantins e parte da bacia do rio Orenoco, estendendo-se por nove países: Brasil, Colômbia, Peru, Venezuela, Equador, Bolívia, Guiana Francesa, Suriname e Guiana. Do total da área, mais de 60\% encontramse em território brasileiro e representam mais de $50 \%$ (cerca de cinco milhões de $\mathrm{km}^{2}$ ) deste país. Nesse, dominam climas quentes e úmidos e as florestas tropicais.

A par dessa aparente unidade como bacia hidrográfica “descobre-se” a existência de uma gama de ecossistemas complexos com diferentes características de relevo, solo, flora, fauna e de processos dinâmicos. Nos estudos sobre a Amazônia legal realizados pelo IBGE/SAE (1995), os mapeamentos de sistemas de paisagens naturais demonstraram não só essa complexidade, na medida em que foram identificados cerca de 104 sistemas e 224 subsistemas, como também a importância de paisagens com características físicas abióticas relacionadas a condições hidrológicas distintas das atuais. São paisagens nas quais, apesar de hoje a cobertura florestal mantê-las em equilíbrio, verifica-se a importância de cicatrizes de des-lizamentos, voçorocamentos e de dissecação generalizada.

A Amazônia, portanto, é caracterizada pela presença de paisagens naturais dicotômicas entre o comportamento hidrológico e de flora e fauna, considerada do ponto de vista global como tropical e a paisagem abiótica de características 
distintas das atuais. Tal fato corrobora a hipótese do quão recentes são as condições tropicais úmidas para a Amazônia e alerta para a fragilidade de sua biodiversidade e, portanto, de seus ecossistemas.

Sendo assim, a transfiguração progressiva dessas paisagens naturais de leste para oeste e de sul para norte com a criação das paisagens "humanizadas", reflete-se na natureza por intermédio da reativação dos processos paleoambientais, como de erosão mecânica e química dos solos, a valorização efetiva das águas de escoamento superficial com o aumento na freqüência de ocorrência de movimentos de massa, dos processos de lixiviação dos solos, a formação de lateritas e perda da biodiversidade. De outro, tem-se o aumento de carga sólida nos canais fluviais para uma mesma ou menor vazão, o que acarreta o assoreamento destes com a diminuição da profundidade e o alargamento dos leitos, com a conseqüente ampliação das áreas de enchentes.

Política e economicamente, a região amazônica brasileira teve seu recorte geográfico institucionalizado como Amazônia legal (Figura 1), a partir de Decreto-Lei de 1966, incluindo além de toda a região Norte (os estados do Amazonas e Pará e, à época, os territórios do Acre, Amapá, Rondônia e Boa Vista) parte sul e oeste do estado do Maranhão, o norte de Goiás (hoje estado do Tocantins) e o estado do Mato Grosso. Esse Decreto-Lei previa tratamento especial nos processos de colonização ali a serem estabelecidos, com vistas à não descaracterização desse espaço geográfico.

A sua delimitação apoiava-se na homogeneidade paisagística dada pela cobertura florestal, embora tenham sido incluídas áreas de cerrados, no conceito equivocado de vazio demográfico e em premissas geopolíticas "de integrar para não entregar" e "abrir estradas é levar o progresso". Os espaços produzidos mostram que muito pouco ou nada foi realizado no sentido de se atender as premissas originais - respeitar as características básicas ecológicas - bem como nos deixam hoje à frente da "descoberta" da existência de sociedades locais que foram, ao longo do tempo, sendo despossuídas e que, a par essa devassa, foram resistindo, construindo e reconstruindo a sociodiversidade amazônica. Com efeito, qualquer tomada de decisão quanto ao futuro desse território passa pela discussão da preservação dos povos indígenas (como, de resto, dos povos da floresta) devido não somente à importância numérica, à diversidade étnica e à enorme extensão de suas terras, mas principalmente à aceitação de sua cultura e de seu trabalho como elo fundamental na conservação e no manejo adequado do meio ambiente.

Ao longo do tempo, esta mesma Amazônia legal tem sido objeto de atribuição de uma infinidade de órgãos que vão do controle ambiental ao ordenamento territorial e que, na maior parte das vezes, acabam por superpor atribuições. Da forma como as atribuições estão presentemente definidas, há a necessidade de que se estabeleçam estratégias de articulação que não se esgotem, como tem sido prática, na criação de comissões de caráter apenas administrativo e pouco eficientes quanto à definição e à implementação de planos e ações governa- 
mentais concertadas. Isso pressupõe uma mudança de enfoque e de atitude, desde os sistemas institucionais de ciência e tecnologia aos de planificação.

Hoje, a Amazônia legal é composta por oito estados (Acre, Amazonas, Pará, Roraima, Amapá, Rondônia, Mato Grosso e Tocantins) e parte do estado do Maranhão, os quais totalizam cerca de vinte milhões de habitantes com um perfil progressivamente urbano (60\% da população da Amazônia legal) (Figura 2 ), caracterizado por um crescimento vegetativo de sua população e no qual as migrações são intra-regionais, flutuando de zonas rurais para as urbanas e ruralrural, sendo este último uma resposta à conversão de novas áreas para pastagem e grãos, como, por exemplo, Rondônia-Roraima e Rondônia-Amazonas. Nesse contingente humano, as populações indígenas remanescentes perfazem um total superior a 160 mil habitantes.

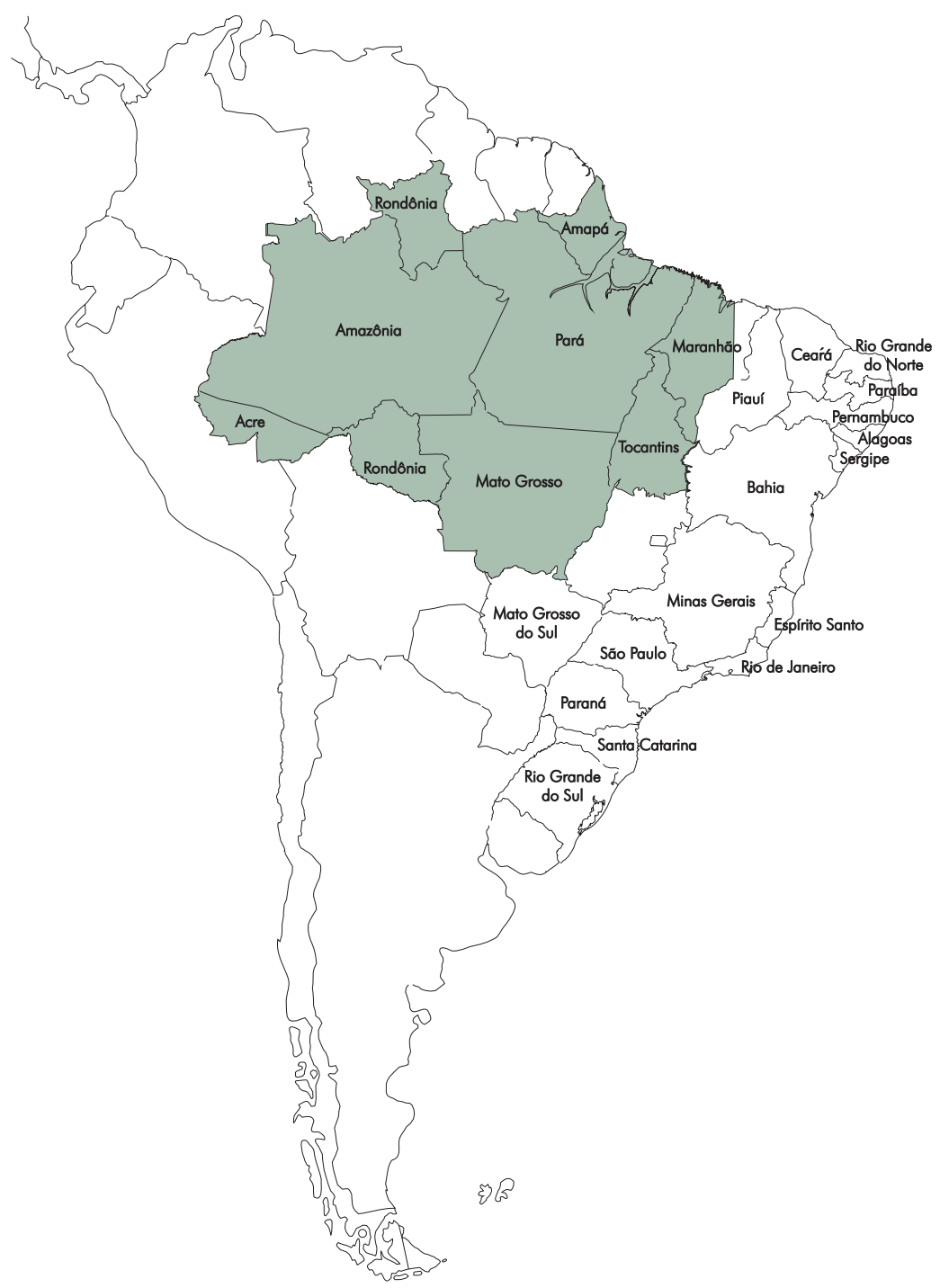

Figura 1 - Mapa de localização da Amazônia Legal. 


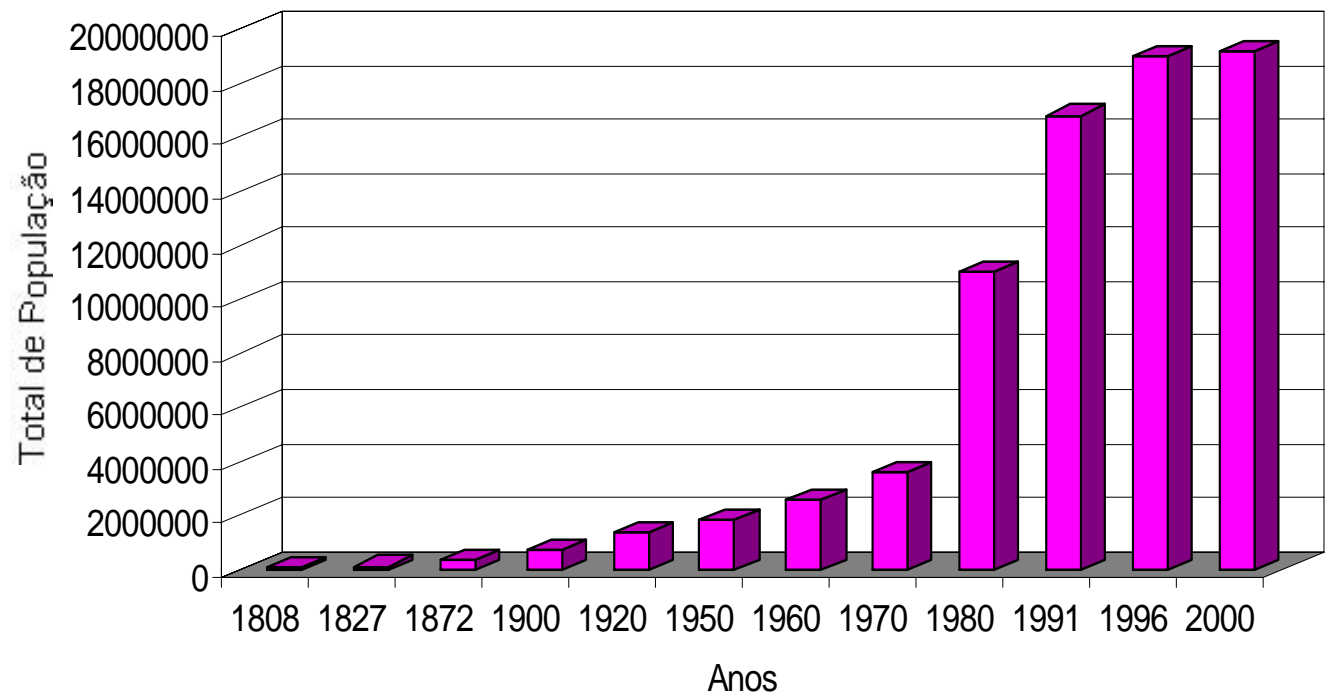

Figura 2 - Crescimento populacional da Amazônia Legal (1808 a 1996).

A sociedade regional é formada por índios, caboclos, pequenos produtores, contingentes populacionais sem terra, trabalhadores urbanos, grandes e pequenos proprietários, empresários tradicionais e modernos. A maior parte desses atores sociais compõe os contingentes de imigrantes que, em diferentes épocas, para aí se dirigiram, configurando outra dimensão da diversidade tão característica dessa área. Trata-se não mais apenas de sua diversidade físico-natural e biológica, mas também da diversidade de povoamento, cultural, econômica e social.

Enfim, há tantas Amazônias quanto a nossa capacidade e/ ou necessidade de percebê-la e/ ou abordá-la permitirem. Entretanto, independentemente do enfoque que se queira dar, há que se aceitar que a Amazônia não é apenas um ambiente ecológico, mas também um ambiente humano, com uma história social, política e econômica que se inicia antes mesmo do descobrimento das Américas. Conseqüentemente, há que se conceituá-la como o produto das relações sociedade-natureza, ao longo de um tempo não só histórico, mas também "pré-histórico", como forma de apreender-se a sua complexidade e, assim, melhor definir os espaços territoriais configurados, que por si só já se demonstram como um macrozoneamento territorial, muitas vezes não desejável, mas existente.

É importante lembrar que o domínio amazônico é, ao mesmo tempo, um dos últimos grandes e ricos espaços pouco povoados do planeta e um dos ecossistemas mais complexos e vulneráveis do planeta, o "que torna o seu desenvolvimento uma incógnita e um desafio às ciências mundial e nacional" (Becker, 1996). Os problemas ecológicos e de pobreza que se configuraram no recorte territorial da Amazônia legal não existem em função do nível de desenvolvimento, mas sim do modelo adotado. É essencial, portanto, a busca de um estilo de desenvolvimento que nos seja desejável. 


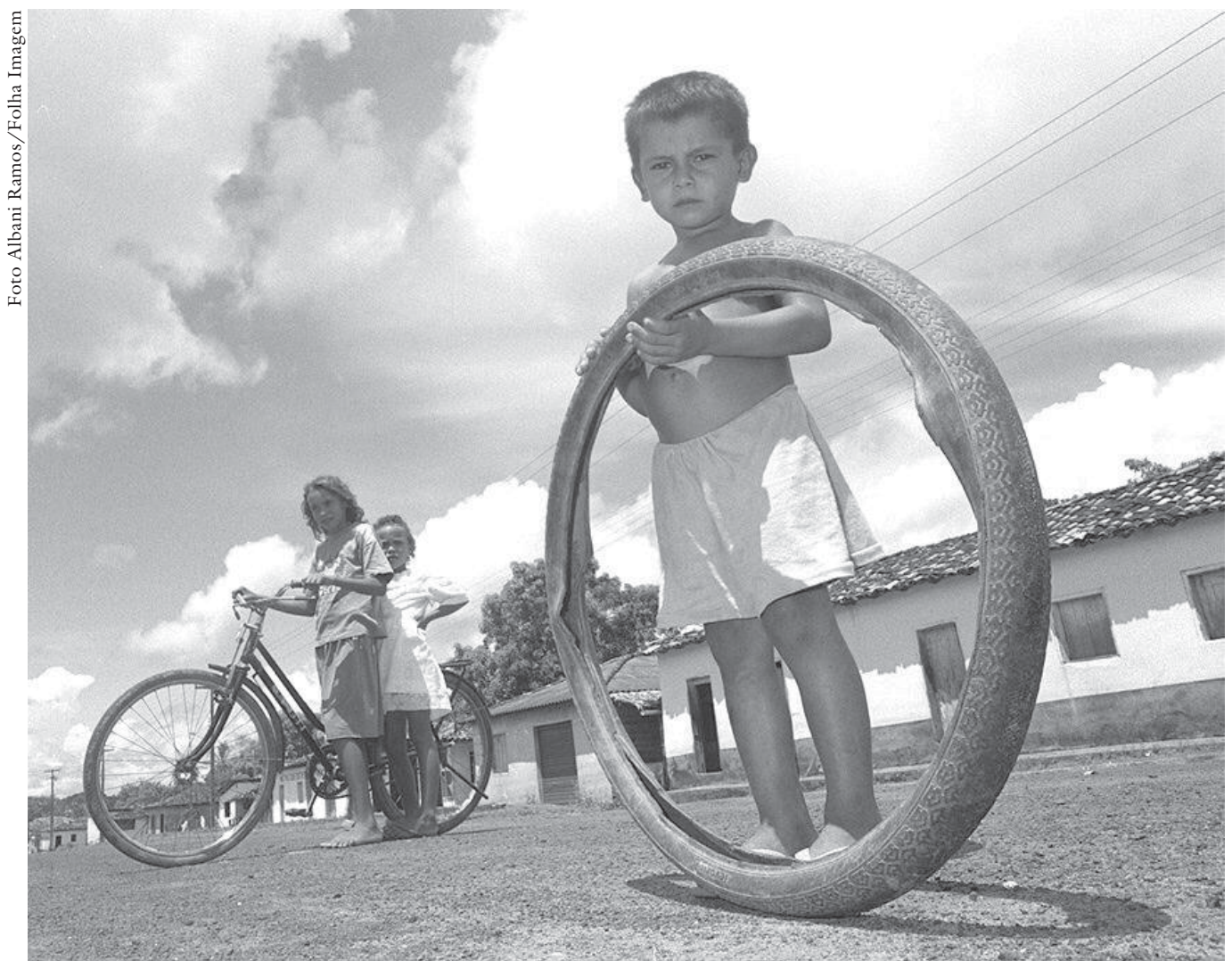

Crianças brincam com bicicleta no município de Presidente Sarney, no Maranbão (MA).

Nesse sentido, fica aqui colocado o questionamento que deve estar presente em qualquer fórum de discussão e em todo pesquisador e tomador de decisão que se dedique ao estudo da Amazônia: qual é a concepção de desenvolvimento que desejamos e propomos para a Amazônia e qual a estratégia produtiva, de conservação e de melhoria de qualidade de vida que, integradas, tornam sustentável esse patrimônio nacional? Não havemos de querer dar continuidade a políticas científicas que, a cada momento, escolheram um tema, um bem ou um produto como o fomentador da grande redenção desse espaço. O tempo tem mostrado que esses tão decantados eldorados (especiarias, mineração, agropecuária) acabaram por construir outros, fétidos, impregnados pelo espectro de morte que os acompanhou e os acompanha.

\section{As forças de transformação}

Discorrer sobre a incorporação e a "humanização" do espaço amazônico é falar dos diferentes devassamentos sofridos por esta região ao longo de sua história de ocupação. Essa expropriação de homem e natureza, em grande parte resultado da idéia de "a grande fronteira de recursos", ao adquirir proporções gigantescas, veiculou o pensamento da existência de recursos inesgotáveis e da quase obrigação de sua exploração.

De outro, o slogan de "vazio demográfico", remetia à noção da necessidade de ocupação de um espaço de dimensões continentais. E, assim, essa região foi 
sendo incorporada de maneira compulsiva, apoiada no tripé da necessidade de progresso, da busca de integração nacional e internacional e do crescimento econômico (Figura 3). São forças transformadoras geradas, na maior parte das vezes, em espaços extra-amazônicos e extracontinentais. A magnitude dessas forças gera demandas capazes de exercerem grandes pressões sobre os grupos sociais aí presentes, tornando-os agentes locais do devassamento.

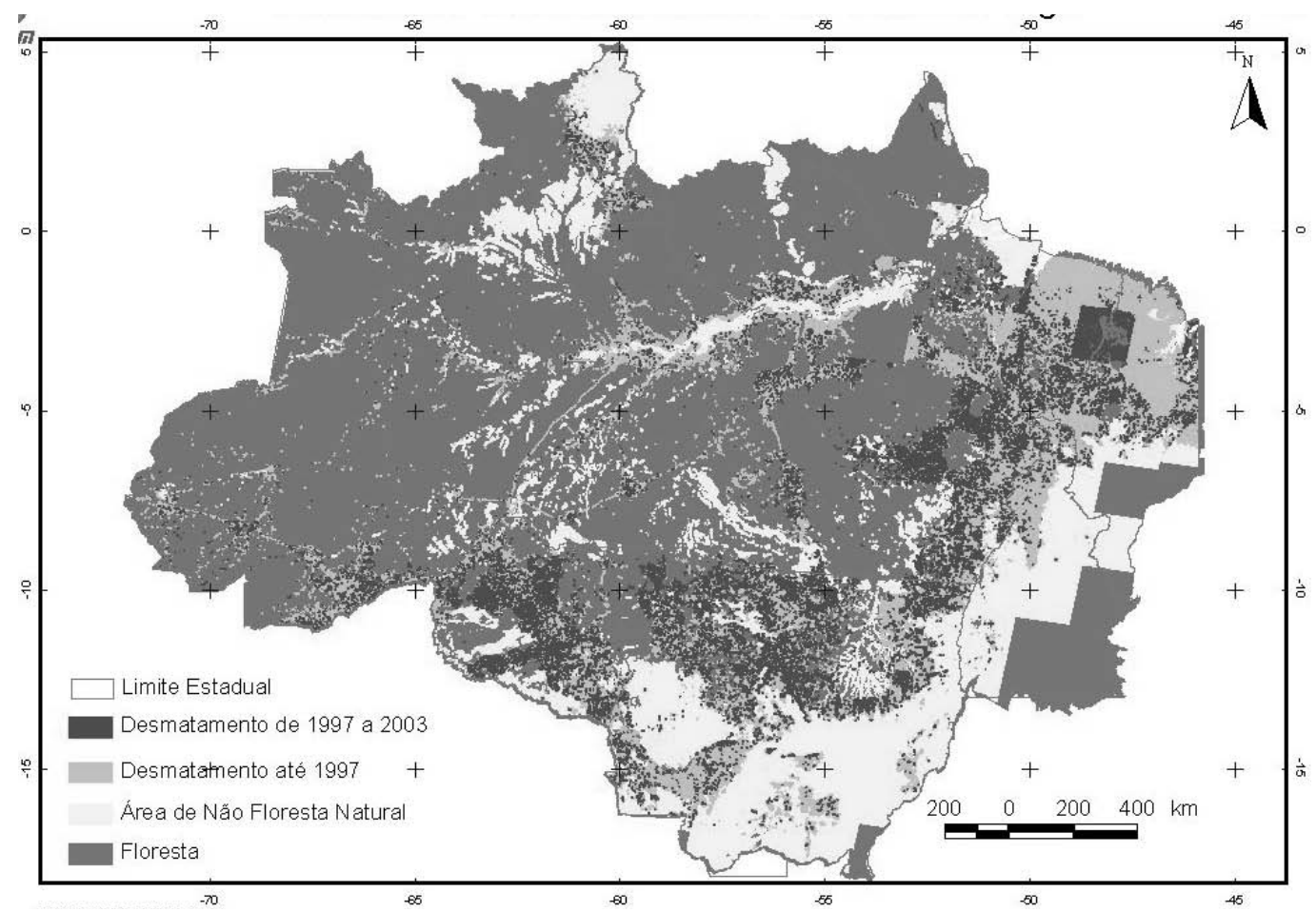

Figura 3 - Crescimento de desmatamento na Amazônia Legal (1997 - 2003).

$\mathrm{Na}$ verdade, esse progressivo devassamento, ao mesmo tempo lúdico e cruel, responde a diferentes demandas externas e internas por matérias-primas e insumos necessários ao modo de produção vigente, bem como à necessidade de resolução de questões sociais em diferentes regiões extra-amazônicas (nordeste, centro-oeste e sul). Como rebatimento desse processo, tem-se uma contínua e progressiva transfiguração da Amazônia expressa pelas taxas de desmatamento que, em alguns momentos, adquire aspectos epidêmicos (Figura 4).

Ao longo desse tempo, inúmeros projetos visando à organização e à integração desse espaço geográfico foram propostos e implantados. Entretanto, pode-se considerar a década de 1960 como o grande marco a partir do qual as transformações promovidas geraram as maiores transfigurações ecológicas e culturais. Como resposta tem-se a penetração e a consolidação do domínio do território, a privatização gradativa de terras, minas e florestas e a organização econômica e política da região. 

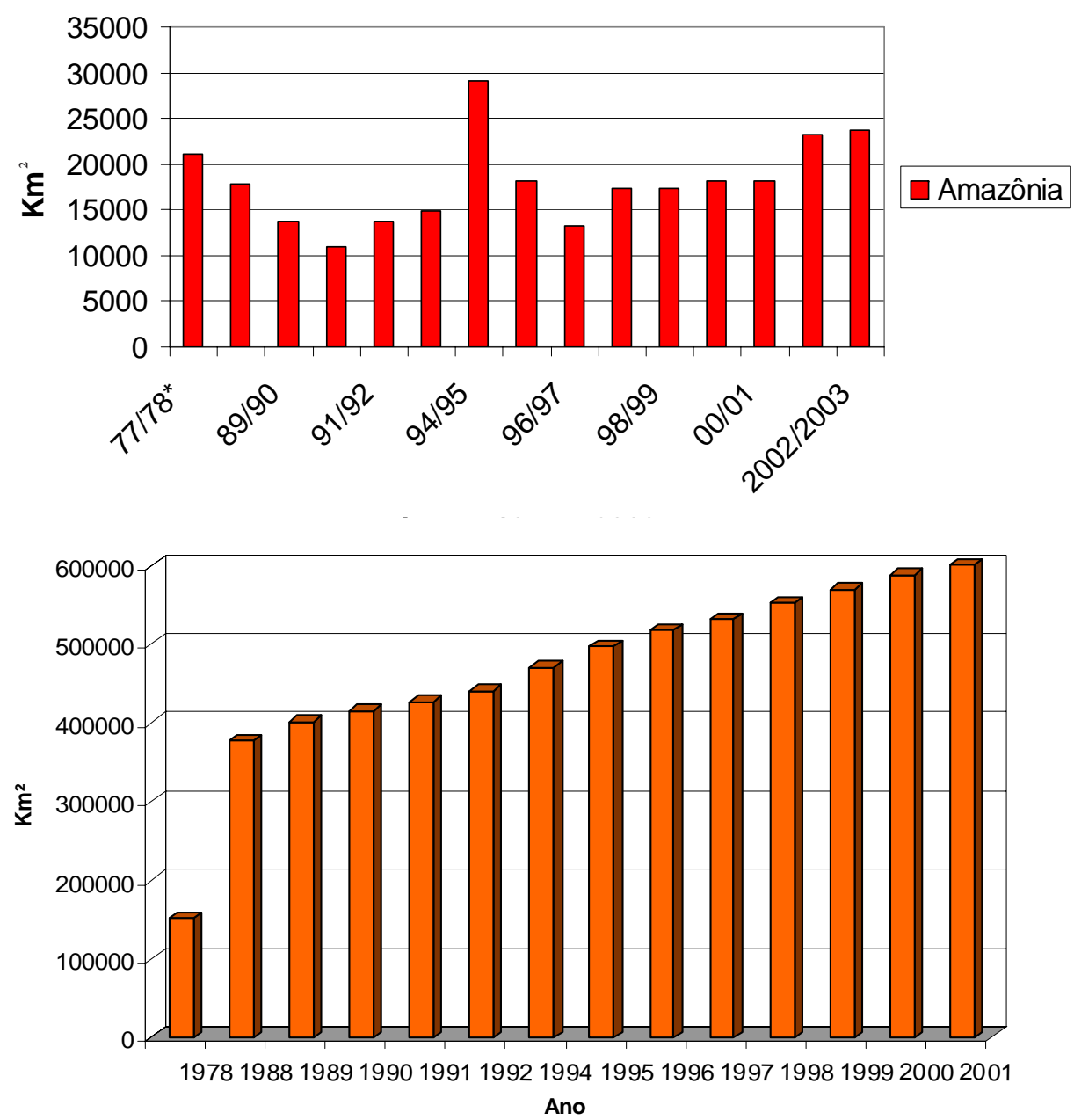

Fonte: Inpe, 2002.

Figura 4 - Extensão do desmatamento bruto na Amazônia Legal (1978 a 2001).

Herdeira do planejamento do estado, no período de sua maior centralização nos anos de 1960 e 1970, a estrutura espacial da Amazônia guarda marcas profundas desse período traduzidas, entre outras, pela forte desigualdade na distribuição social de seus recursos naturais, dentre os quais se destaca a terra. Matriz do processo de exclusão social, as distorções nas formas de apropriação e uso da terra levaram a uma desterritorialização de grupos nativos - índios e caboclos acompanhada de intensa mobilidade populacional que imprime um caráter de instabilidade e não dinamismo, que a própria condição de fronteira naturalmente já transmitiria à ocupação da Região. Tal instabilidade exerce grande pressão sobre o sistema natural sem, contudo, equipar o território para sua eventual ocupação em bases sustentáveis.

Por outro lado, a degradação do meio físico-biótico acentuou-se na Amazônia, quando este se viu transformado, por meio da política pública, em capital 
especulativo à espera de valorização futura, ou em matéria-prima visando à obtenção de divisas necessárias à redução da dívida externa do País.

Na última década, contudo, uma vez esvaziado o poder do Estado pela convergência da escassez de recursos em nível internacional, do crescente endividamento interno e externo e da conseqüente agudização do déficit público, a União perde seu poder de intervenção em grande escala sobre esse vasto território, à medida que se sente fragilizada para agir sobre as conseqüências de uma estratégia de ocupação equivocada.

Tal intervenção era feita tanto diretamente, por meio de grandes obras de infra-estrutura, conjugadas ou não a algum tipo de política compensatória à população local, quanto, indiretamente, via concessão de subsídios, quando se abria mão de parte da arrecadação de tributos para atrair investimentos privados e, com isso, empurrava-se, aceleradamente, a fronteira agrícola especulativa.

A crise econômico-financeira do Estado confunde-se e potencializa, no presente, a própria crise ambiental vivenciada pela região amazônica, na medida em que a União torna-se impotente para gerir as contradições, de toda ordem, surgidas e/ ou desencadeadas no curso de sua ocupação.

Há, atualmente, uma grande contradição vivida pelo setor público brasileiro: a implementação de medidas regulamentadoras de caráter ambiental exige instituições públicas fortes, sólidas e legitimadas política e socialmente, mas o Estado está em crise e autoproclama sua incapacidade.

As expansões do garimpo, do narcotráfico e do cinturão de pobreza em torno dos centros urbanos são testemunhos concretos da desordem ambiental na Amazônia contemporânea, alicerçada na incapacidade de se absorver, em bases minimamente estáveis e produtivas, a mão-de-obra nativa e, principalmente, migrante atraída para a fronteira pelo modelo de desenvolvimento regional implementado.

A insustentabilidade econômico-social de tal modelo traduz, pois, a um só tempo, a crise ambiental, do Estado e o esgotamento do paradigma desenvolvimentista, no interior dos quais se contextualiza a discussão acerca das relações sociedade-natureza nos dias atuais. É dentro desse quadro que se deve entender a desaceleração no ritmo de incorporação de terras à fronteira agrícola, arrefecido "espontaneamente" pelo quadro recessivo da economia do País, como pelas alterações ocorridas na política de subsídios à implantação de projetos agropecuários, notadamente em áreas de floresta, que sinalizam mudanças verificadas na forma de atuação do Estado nessa região.

Com efeito, o ideário do desenvolvimento sustentável absorvido pela administração pública como discurso obrigatório acaba adquirindo expressão política concreta, seja pela pressão exercida pelos países centrais, oficialmente, seja pelo intermédio de poderosas organizações não-governamentais (ONG's), que atuam diretamente sobre as agências internacionais de financiamento e/ ou em escala local, em comunidades e movimentos nativos, com os quais estabelece vínculos 
diretos, garantindo-lhes certo grau de autonomia em relação ao poder político estabelecido.

Com a preservação de sua sociobiodiversidade mundialmente defendida por agentes sociais diversos, interessados ou não em sua exploração futura, $\mathrm{o}$ fato é que a Amazônia brasileira transformou-se em um espaço estratégico na definição da forma de inserção do País no processo de globalização da economia (Becker, 1996), cabendo ao componente ambiental um forte apelo no que tange ao relacionamento Norte-Sul relativamente à transferência de tecnologia, às trocas comerciais e ao equacionamento da dívida externa.

Por tudo isso, altera-se a forma de atuação do Estado na região, tanto mais que, internamente, esta passa a ser contingenciada, também, pela tendência à descentralização político-administrativa assentada na redefinição de forças que operam no nível do mercado e na própria reformulação constitucional, afetando a repartição tributária em benefício de estados e municípios. Soma-se a essas transformações a crescente participação de segmentos sociais organizados, com ou sem a liderança da Igreja, do movimento sindical e das ONG's, que estão a exigir novas práticas políticas, objetivando a melhoria social subjacente à tese do desenvolvimento sustentável.

A década de 1990 traz em seu bojo um novo referencial quanto ao papel dessa região, causada pelas transformações da ordem econômica e política mundial. Configura-se uma nova fase referenciada agora pela revolução científico-tecnológica, pela crise ambiental e pelos movimentos sociais. A transição dessa mudança caracteriza-se em dois vetores de transformação regional, o tecno-ecológico e o tecno-industrial, resultantes da coalescência de projetos de múltiplos atores e parcerias. O primeiro vetor envolve projetos preservacionistas da legítima consciência ecológica e da geopolítica ecológica e projetos conservacionistas, de populações locais aliadas a redes transnacionais, que constituem experiências alternativas diversas, revelando o movimento de organização da sociedade civil. $\mathrm{O}$ vetor tecno-ecológico manifesta-se na importância de novos atores no cenário político, particularmente as ONGs, e de novos recortes territoriais, correspondentes à multiplicação de vários tipos de áreas reservadas e experiências comunitárias.

Se por um lado essas transformações podem ser consideradas como produto da própria história local de ocupação humana, de outro refletem a atuação de diferentes agentes externos, em escala planetária, que provocaram e provocam modificações na dinâmica do espaço amazônico.

\section{Os devassamentos da Amazônia}

Embora as datas para a periodização das diferentes fases históricas de transfiguração da região amazônica brasileira possam variar, todos os autores são unânimes em identificar de quatro a cinco fases, a saber: a de conquista e posse; a de ocupação; a de exploração; a de valorização e de integração. A cada uma dessas fases corresponde uma política demográfica de migração que busca, por meio do 
encaminhamento de levas humanas para esse espaço vazio, solucionar problemas, tais como a ocupação de fato desse vasto espaço regional; a resolução de problemas sociais vinculados ao acesso à terra de grandes segmentos sociais de pequenos produtores em regiões extra-amazônicas; e o atendimento a demandas de mercados externos por matérias-primas e insumos. A cada um desses momentos correspondeu uma forma de devassamento do homem e da natureza nesse espaço amazônico.

O primeiro devassamento foi o da floresta inundável localizada ao longo dos eixos fluviais navegáveis. Buscavam-se, por um lado, as "drogas do sertão" (canela, cravo, anil, cacau, raízes aromáticas, sementes oleaginosas, madeiras, salsaparrilha etc.), utilizáveis na alimentação, condimentação, construção naval e na farmacopéia da Europa Ocidental dos séculos XVII e XVIII e, por outro, a expansão do território português. As manifestações de povoamento são baseadas nos núcleos militares e coloniais e nas missões religiosas (São Gabriel da Cachoeira, Barcelos, Tefé, Santarém etc.). As pressões e potencialidades de mercado levam a que a metrópole induza a passagem da prática de coleta dessas drogas a seu cultivo.

A necessidade de mão-de-obra leva a que os colonos, principalmente do Maranhão, iniciem um movimento no sentido de caça ao índio. $\mathrm{O}$ embate entre jesuítas, defensores dos indígenas, e colonos maranhenses produtores de açúcar, fumo e outros produtos, provoca uma maior interiorização da penetração humana, que agora estende seus tentáculos por sobre áreas de florestas de terra firme, descobrindo novas potencialidades, as especiarias. Parte dessa época é conhecida como o "Ciclo de Drogas do Sertão".

O segundo grande devassamento ocorreu entre as últimas décadas do século XIX e as duas primeiras do século XX, como resultado de duas grandes demandas: a Europa e os Estados Unidos requeriam, de um lado, volumes maciços de borracha para a confecção de objetos de uso doméstico, pneus, materiais bélicos e para a construção naval; e, de outro, havia a necessidade de se resolver problemas configurados na região nordestina devido à prolongada seca ocorrida entre 1877 e 1880. É a fase de penetração e integração do sudoeste da Amazônia, datando desse período a incorporação do hoje estado do Acre. Foi o "Ciclo da Borracha".

A associação dessas demandas externas nacional e internacional provoca um incremento sensível do contingente populacional local. O contingente humano cresce de 127 mil habitantes, em 1823, para cerca de um milhão e quatrocentos mil habitantes, por volta de 1920. Estes vão engrossar as fileiras de mãode-obra que se derramam por sobre aquelas áreas de floresta ombrófila densa, onde se verificam maior ocorrência da Hevea brasiliense (seringueira). Dentre essas áreas, o Acre apresentará o maior fluxo de imigração.

A partir dos anos de 1920-1930 tem início a invasão das frentes pioneira agropecuária e mineral, que penetram através dos enormes vãos das organizações 
extrativas da borracha e da castanha. Essas atividades atendem a demandas, predominantemente locais a regionais e resultam da necessidade de se atender a um mercado consumidor local que se configura e de complementar os recursos daqueles que vivem de uma agricultura de subsistência e/ ou do extrativismo vegetal.

Embora as frentes pastoris tenham, ao longo de todo o tempo, estado presentes na Amazônia, tinham como limite de penetração a floresta. Toda a expansão pastoril verificada até este momento ocorreu em áreas de cobertura vegetal de cerrado e de campos. Por suas características de expansão sobre pastos naturais, por seu papel secundário e pouco exigente em número de mão-deobra, até a década de 1970 essa atividade exerce menor pressão sobre o espaço florestal amazônico.

Entretanto, a chegada da década de 1970 inverte essa situação e passa a configurar o terceiro grande devassamento. A partir desse momento, a "descoberta" da riqueza mineral e da pobreza dos solos tornará essas duas "frentes" responsáveis por um novo boom na transfiguração desse mosaico ecológico e sociocultural ao mesmo tempo em que se incrementa o slogan de "integrar para não entregar”. É a explosão das estradas que cortam esse espaço amazônico. É a era dos incentivos fiscais e das grandes migrações induzidas para o Eldorado prometido.

A abertura da rodovia Belém-Brasília nos anos de 1960, configura um eixo norte-sul, a partir do qual se articularam vias secundárias preexistentes ou que vieram a ser concluídas e que redefiniram todo o sistema de acesso à região, da circulação das frentes de expansão e das mercadorias no sentido leste-oeste.

A construção dessa via de penetração levou à aceleração da expansão de frentes camponesas seguindo a rodovia em direção ao Araguaia e ao Xingu, começando a sinalizar sensíveis alterações na Amazônia Oriental. Estas, contudo, só se interiorizaram com maior intensidade uma década após, com a abertura da Transamazônica e da Cuiabá-Santarém, e com os projetos de colonização oficial planejados ao longo dessa primeira e atrelados à Política de Integração Nacional (PIN).

Ao mesmo tempo, nesse período, acelerou-se a expulsão de grande número de pequenos agricultores nordestinos. Eles foram "orientados" e "estimulados" a avançar sobre terras pré-amazônicas e amazônicas onde, segundo a propaganda, havia muitas "terras livres".

O ritmo e a intensidade com que se realizou tal ocupação significou, em geral, uma ruptura profunda com as atividades que se reproduziam no "vazio demográfico", dentro de uma diversidade social e econômica que abrigava basicamente uma população constituída de índios, de ribeirinhos e de remanescentes nordestinos, muitos dos quais acaboclados, trazidos pelos sucessivos picos da economia extrativista.

No período que vai de 1960 a 1980 o contingente populacional amazônico passa de 2,6 milhões para onze milhões. O boom populacional é resultante novamente do saldo migratório. 
Na tentativa de dar maior organicidade a esse processo de ocupação é criado, em 1970, o Incra, cujo objetivo era promover e executar a reforma agrária e promover, coordenar, controlar e executar a colonização. Segundo o Ibase (1985) o Incra teria deslocado para a região amazônica no período entre 1970 e 1974 cerca de quatrocentos mil colonos.

Nesse intenso processo de ocupação que se configurou nas duas últimas décadas, a colonização dirigida aparece como uma das formas mais significativas. De maneira geral, os projetos de colonização não apresentam um padrão uniforme, diferindo em relação à área ocupada e à natureza da iniciativa. Embora componham uma mesma política governamental, expressam aspectos distintos de acesso à terra via colonização.

Os projetos de colonização oficial, executados pelo governo, aparecem de forma dispersa na Amazônia Oriental (Altamira, Itaituba, Marabá, Carajás II e III - Pará; Barra do Corda - Maranhão). Enquanto na Amazônia Ocidental tendem a concentrar-se em Rondônia. Podem ser de três tipos: integrados de colonização, de assentamento dirigido e de assentamento conjunto. Perfazem $73,4 \%(7.104 .285,3 \mathrm{ha})$ das terras apropriadas para essa finalidade.

Já os projetos de colonização particular, executados por iniciativa privada, ocorrem predominantemente em Mato Grosso, destacando-se os de Sinop, Alta Floresta e Juína. Esses projetos significam $26,6 \%$ do total $(2.573 .485,6$ ha).

Dos órgãos ligados aos problemas fundiários na Amazônia, afora a ação do Incra, cabe mencionar a atuação do Getat e do Gebam, no interflúvio AraguaiaTocantins e no Baixo Amazonas. Sua ação, embora planejada no sentido de anteceder à ocupação desordenada de áreas ainda "efetivamente vazias", frustrou-se em face da acelerada expansão de uma fronteira agrícola caracterizada pela extrema mobilidade de sua população.

Ao adentrar os anos de 1980, uma nova fase se configura como reflexo da nova ordem econômica mundial, ditada por um mercado de matérias-primas estruturado em escala mundial. O comprometimento dessa economia ocasionou o resgate de recursos tornados escassos contemporaneamente (madeira, energia hidráulica), a utilização de outros de crescente demanda pela tecnologia moderna (alumínio) além do barateamento de matérias-primas tradicionais abundantes na área (minério-de-ferro).

Do ponto de vista nacional, a década de 1980 representa a implantação de uma política de modernização desse território, visando à industrialização da Amazônia e à exploração de seus recursos minerais em bases modernizadas. É nessa década que se implantará o Programa Grande Carajás (PGC), considerado tanto em termos de extensão física $\left(900 \mathrm{mil} \mathrm{km}^{2}\right)$, como de investimentos projetados, um dos maiores projetos integrados de desenvolvimento jamais encetado por um país em desenvolvimento (Hall, 1990).

No seu bojo, esse novo projeto liderado pelo Estado traz demandas por madeiras e energia hidráulica, promove a abertura de áreas para exploração mi- 
neral e propicia uma nova mobilidade da população no espaço amazônico. Na esteira dessas demandas, a nova mobilidade do contingente populacional verifica-se dentro da própria região amazônica. Deslocam-se principalmente maranhenses. São estimulados em direção às áreas onde são necessários como mão-deobra na construção da infra-estrutura (estrada-de-ferro Carajás; área da mina, indústrias siderúrgicas etc.) e, futuramente, para as indústrias.

A interação entre as demandas, a exploração de recursos e a necessidade de mão-de-obra provoca uma "desorganização" espacial dos segmentos sociais despossuídos que passam a ver na exploração desse bem uma alternativa de sobrevivência. Observam-se levas migratórias internas e extra-amazônicas (centrooeste e sul). Como conseqüência, tem-se a explosão da exploração do ouro (garimpos e pequenas empresas), do qual o exemplo mais conhecido é Serra Pelada. O boom máximo é atingido em 1985, quando, em torno dessa área, tem-se mais de quinhentas mil pessoas amontoadas em aglomerações tais como Marabá, Eldorado do Carajás, Curionópolis, Parauapebas, Rio Verde. É a segunda grande transfiguração ecológica e humana da Amazônia Oriental.

Como resultado dessas transformações tem-se, para o período compreendido entre 1960 e 1991, um crescimento do contingente populacional da ordem de catorze milhões de habitantes, significando uma taxa de crescimento total de $550 \%$.

Como resposta a esse processo de devassamento progressivo tem-se, para 1991, um total de 14,07\% do território amazônico brasileiro impactado e/ ou desmatado, incluindo as formações vegetais florestais e não florestais. Verificouse que, entre 1976 e 1991, foram impactadas e/ ou desmatadas cerca de 35,61\% da área de ocorrência de formações vegetais de Florestas Estacio-nais e Ombrófilas e 20,41\% das áreas de contato Floresta Ombrófila/ Floresta Estacional (Figura 5 ). Esses valores correspondem ao percentual total da área da Amazônia brasileira convertida em pastagens, áreas agrícolas, exploração madeireira, exploração mineral, garimpo, extrativismo vegetal e áreas urbanas.

Por fim, a década de 1990 parece trazer em sua esteira um novo referencial quanto ao papel dessa região, causada por novas transformações da ordem econômica e política mundial. Configura-se uma nova fase referenciada agora pela revolução científico-tecnológica, pela crise ambiental e pelos movimentos sociais. Nesta década, o crescimento populacional via migração torna-se um fato histórico, substituído por um crescimento vegetativo e mobilidade populacional intraregional. Um quarto devassamento gestado durante a década de 1980 se configura na década de 1990 no bojo do slogan da "globalização", no reconhecimento pelas forças de transformação econômica da finitude dos recursos naturais, na valorização econômica de bens como a água, a biodiversidade e na consolidação de uma nova faixa de produção de grãos, a zona intertropical. Esta fase sem paralelo de expansão, na qual os incentivos fiscais passaram a desempenhar um papel secundário, ou seja, o governo como indutor do desenvolvimento foi subs- 
tituído pela iniciativa privada - cujas atividades econômicas como a retirada de madeiras nobres, a mineração, a pecuária e, sobretudo, o agronegócio - tornaram-se lucrativas. A contastação de que a rentabilidade dos negócios privados é, nos dias de hoje, a força principal que impulsiona a expansão e a transformação das antigas fronteiras agrícolas já foi detectada por vários autores (Mattos e Uhl, 1994; Margulis, 2003; Alencar et al., 2004).

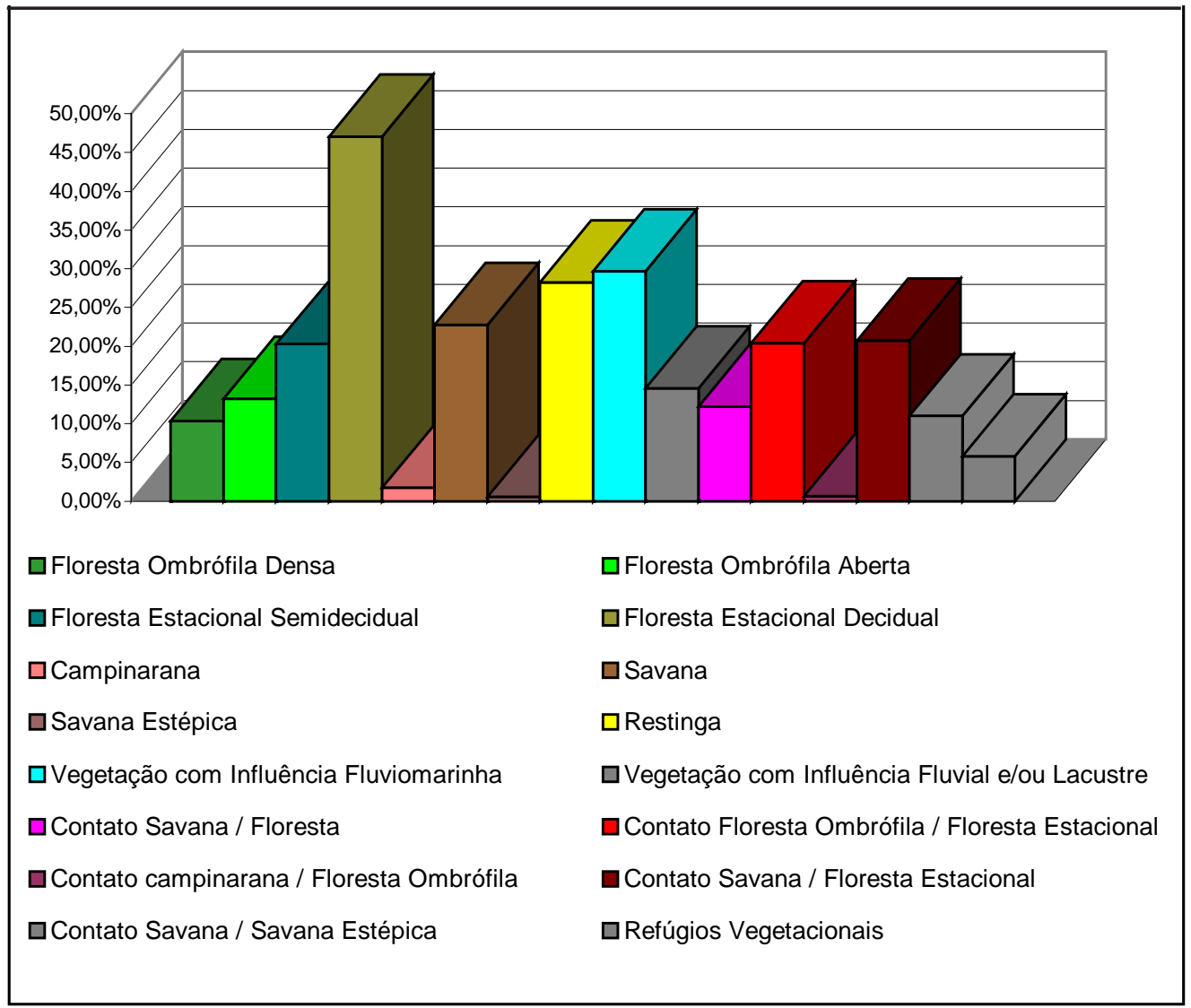

Figura 5 - Percentual impactado e/ou desmatado dos diferentes tipos de cobertura vegetal na Amazônia Legal (1976 a 1991).

As forças transformadoras antes exclusivamente externas mesclam-se a demandas internas nacionais e locais. A Amazônia torna-se o produto de demandas de escalas locais, regionais, nacionais, internacionais e planetárias (Figuras $6 a \mathrm{e}$ b). O seu futuro é o futuro do mundo.

Nesse novo contexto, em que o vetor tecno-ecológico caracteriza o modo de produção, a Amazônia torna-se o centro da discussão mundial. Segundo Becker (1996),

todos os elementos constantes desse vetor estão presentes no Brasil e, com mais clareza, na Amazônia, que se tornou a síntese contraditória dos modelos industrialista e ecodesenvolvimentista dominantes no final do milênio. Para 
esse novo modo de produzir, a natureza se valoriza como capital de realização futura; para as populações nativas e movimentos ambientalistas elas têm valor como fonte e meio de vida, enquanto é ainda base essencial de recursos para segmentos produtores e para a sociedade brasileira em geral.

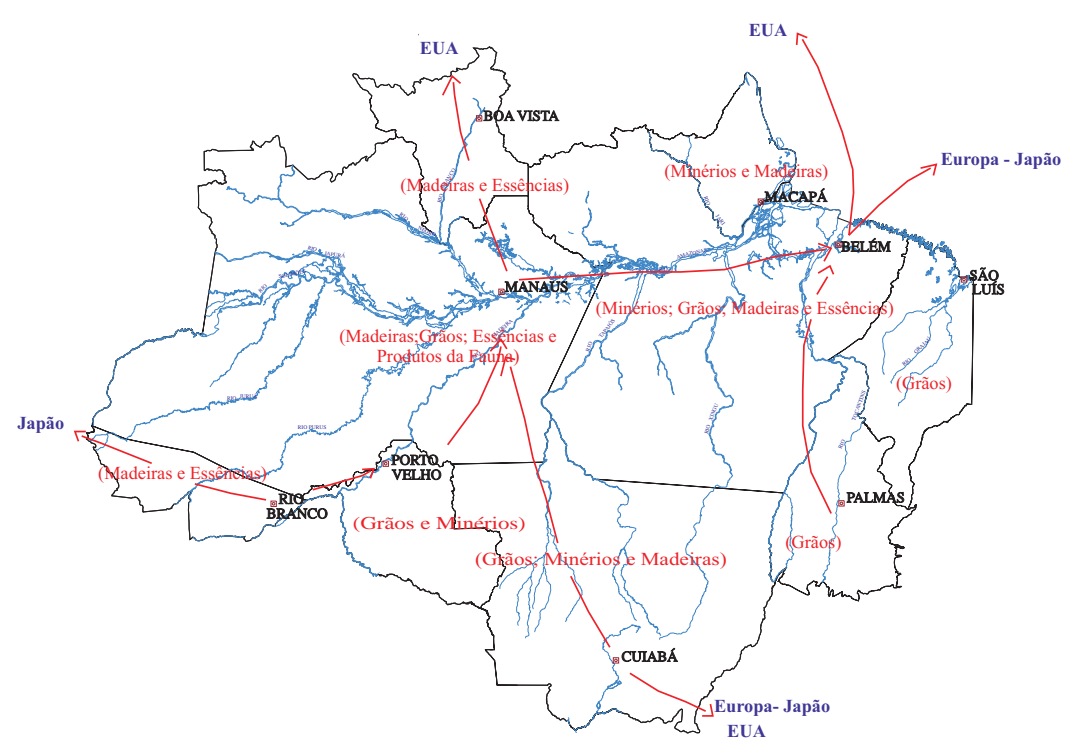

Figura $6 a$-Demandas atuais em escala internacional.

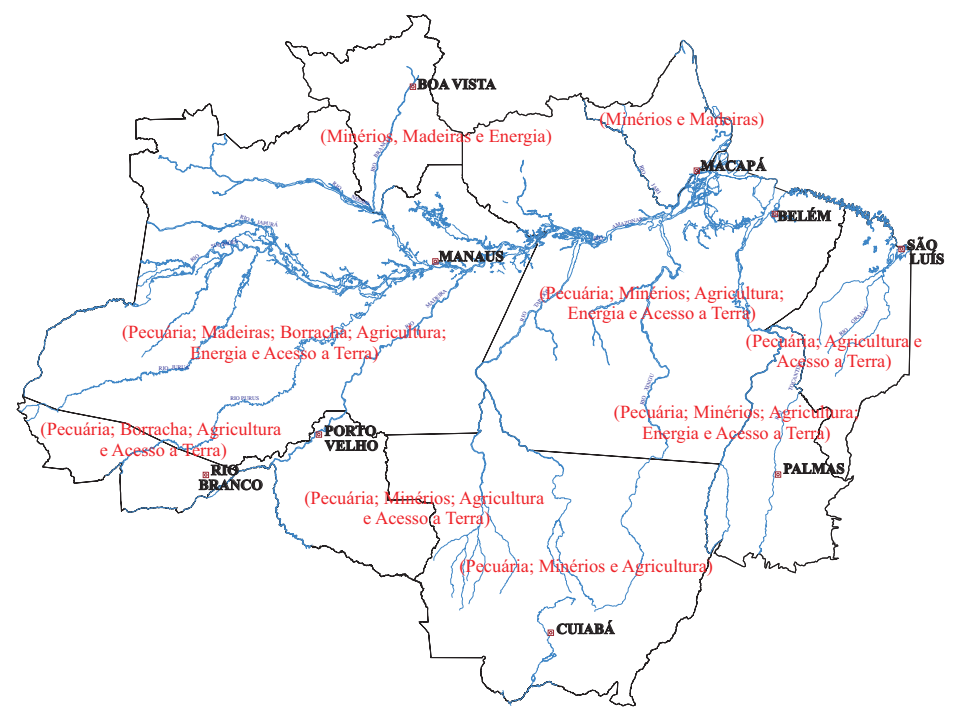

Figura $6 b-$ Demandas atuais em escala nacional e local.

Entretanto, apesar de o vetor tecno-ecológico emergir como discurso que parece permitir a preservação desse espaço geográfico, verifica-se, por outro lado, uma acentuação de demandas econômicas externas por matérias-primas básicas (principalmente madeira) e produtos primários (grãos) que voltam a exercer uma forte pressão sobre essa região em face do esgotamento de outras áreas. Estas se 
expressam por uma nova retomada do desmatamento com a incorporação progressiva de áreas de florestas e de áreas em diferentes estágios de regeneração secundária, principalmente nas regiões de contato floresta estacional decidual/ floresta ombrófila aberta e floresta estacional decidual/ savana, demonstrada, no total, pelas taxas de desflorestamento observadas pelo Inpe para o período.

Se observarmos a taxa média de desflorestamento por estado (Figura 7), verificaremos que os estados de Mato Grosso, Pará e Rondônia foram aqueles que apresentaram maior crescimento progressivo das taxas de desflorestamento para o período que se inicia em 1991. Em contrapartida, o crescimento demográfico urbano e rural na Amazônia Ocidental e Oriental, a partir da década de 1980, mostra um processo crescente de urbanização de sua população, liderados pelos estados do Amazonas e Mato Grosso, seguido em menor escala por Rondônia e Acre (Figuras $8 a$ e $b$ ) e que se consolidam na década de 1990.

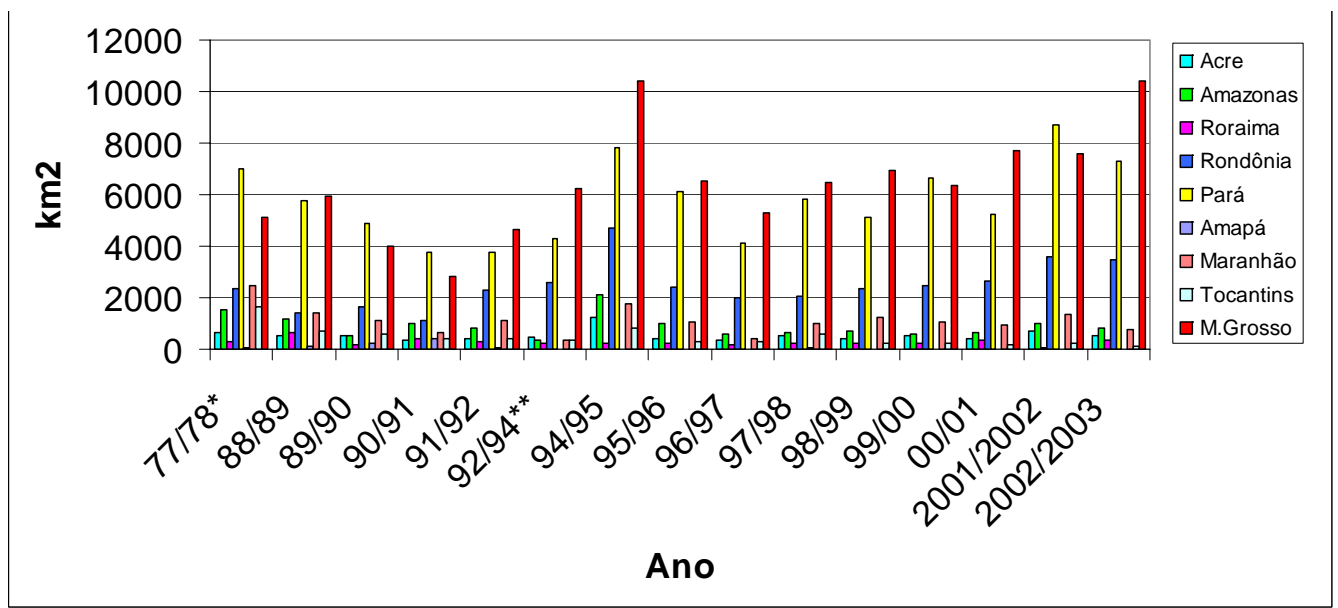

Figura 7 - Desmatamento anual por estado - Amazônia $\left(\mathrm{km}^{2} / \mathrm{ano}\right)$

Tal fato nos remete à hipótese de que o avanço do desmatamento não é produto da pressão demográfica direta, mas sim de forças econômicas transformadoras referenciadas por pacotes tecnológicos excludentes de grandes quantidades de mão-de-obra. Tais forças transformadoras representam grupos de pressão tanto em nível local, regional quanto internacional.

Essa hipótese é corroborada pelos tipos de demandas em escala internacional e nacional que exercem maior pressão sobre essa região. As maiores são representadas pela madeira, pecuária e grãos, atividades pouco absorvedoras de mão-de-obra, mas com alta capacidade espacial de destruição do mosaico ecológico e de desestruturação das populações tradicionais amazônicas. A produção de grãos, embora represente uma demanda recente, vem se expandindo em áreas remanescentes do contato floresta ombrófila aberta/ savana, no norte de Mato Grosso e sul do Pará I (IBGE, 1995). Hoje representam áreas sob influência direta e indireta da agro-indústria da soja consolidada em terras do Mato Grosso e 
Maranhão e expandindo-se no sul do Pará. Mais recentemente, uma nova frente se estabelece às expensas de vegetação primária e de invasão de unidades de conservação e de terras indígenas no sul do Amazonas, a partir de Rondônia. Essa nova ordem de devassamento se expressa principalmente pelo recrudescimento dos conflitos de terra e também pelo crescimento desordenado das cidades, que em alguns lugares da Amazônia chegaram a apresentar crescimento relativo da ordem de 7.000\% para o período 1980-1991 (IBGE, 1995). Essas aglomerações urbanas passam a ser o locus de um processo de ruptura étnico cultural com a conseqüente perda de identidade por parte de segmentos nativos, longamente adaptados aos ecossistemas regionais.

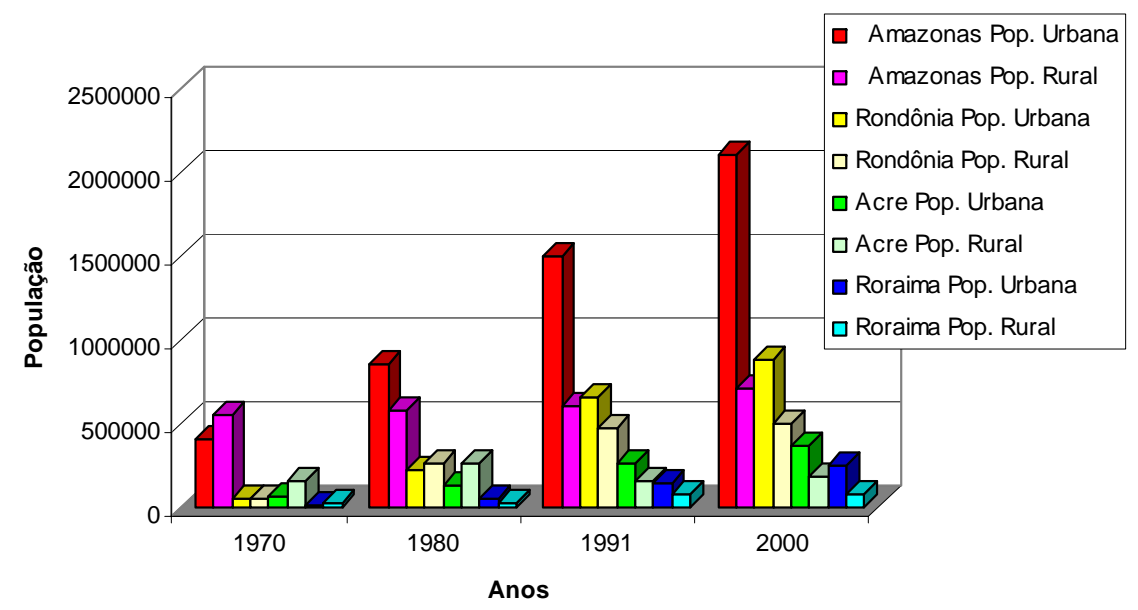

Figura 8a-Crescimento demográfico urbano e rural por estado na Amazônia Ocidental (1970-2000).

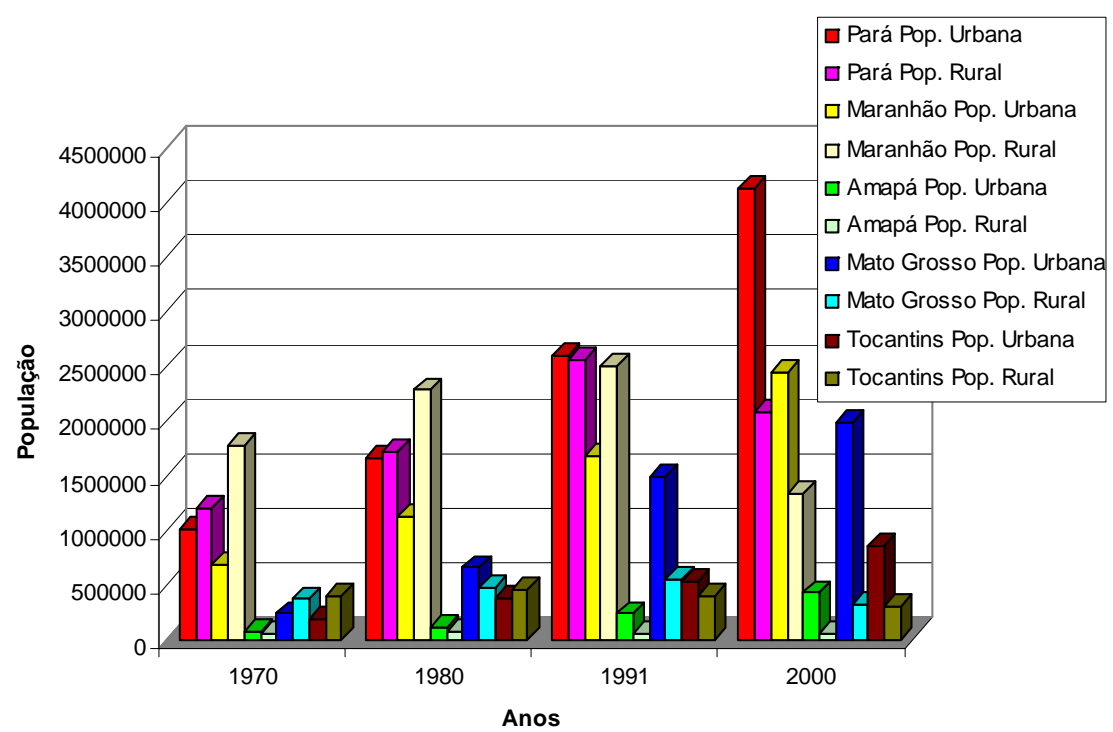

Figura 8b-Crescimento demográfico urbano e rural por estado na Amazônia Oriental (1970-2000). 
Dentro desse quadro urbano complexo surgem questões de saúde, tendose observado, nessa última década, uma elevação sensível na incidência de endemias, principalmente malária, leishmaniose tegumentar, febre tifóide, leptospirose e hanseníase (IBGE, 1995).

O exposto mostra, inequivocamente, a importância dos diferentes segmentos sociais na transfiguração progressiva do domínio amazônico e das forças transformadoras externas capazes de engendrar processos pouco controláveis em nível regional e nacional.

\section{Considerações finais}

O exposto mostra que a análise das forças de transformação dos ecossistemas amazônicos justifica-se, na medida em que a instituição dominante nesse processo tem sido, invariavelmente, um poder externo à região, atuando em resposta ao contexto internacional e à situação nacional. Historicamente, a política territorial sempre esteve associada a interesses econômicos, apoiados na premissa de que o progresso é entendido como crescimento econômico e prosperidade infinita e baseados na exploração de recursos naturais, percebidos como igualmente infinitos.

Contemporaneamente, a Amazônia expressa o conflituoso processo de transição decorrente das rápidas e incertas transformações do sistema capitalista mundial e do esgotamento do modelo nacional-desenvolvimentista dirigido pelo Estado. Transição que, em termos da relação sociedade-natureza, corresponde ao esgotamento do paradigma da economia de fronteira e à emergência de um novo, o desenvolvimento sustentável, que se concretiza em dois vetores de transformação regional resultantes da coalescência de projetos de múltiplos atores, cujo conhecimento é essencial para qualquer tomada de decisão política.

Nesse contexto, há que se realizar a retomada do planejamento em novas bases, pautadas em parcerias com o setor privado e a sociedade civil, considerando as tendências dos vetores de transformação e uma nova estratégia de ação.

Significa reconhecer, em primeiro lugar, o pluralismo existente na região, tirando partido da sua diferenciação interna com vistas ao desenvolvimento sustentável de suas potencialidades. Há que reorientar o vetor tecno-industrial nessa direção, segundo experiência já em curso. No caso do vetor tecno-ecológico, o acesso ao mercado e o progresso técnico são essenciais para sua viabilização.

Em segundo lugar, há que reconhecer a escala de atuação como a Amazônia Sul-Americana. Não apenas pela presença dos ecossistemas florestais e gêneros de vida a eles associados, ou pelas economias fronteiriças já existentes, mas também pelas amplas possibilidades de intercâmbio de energia, produtos, ciência e tecnologia, e de acesso a novos mercados.

Finalmente, uma estratégia de escala local há que ser concebida, capaz de promover a integração interna da região, articulando suas diferentes "ilhas", bem como sua integração externa com o conjunto do território nacional e com a Pan-Amazônica, por meio da qual se poderá alcançar o Caribe e o Pacífico. 


\section{Referências}

ALENCAR, A.; NEPSTED, D.; MC GRATH, D.; MOUTINHO, P.; PACHECO, P.; VERA DIAZ, M. D. C e SOARES FILHO, B. "Desmatamento na Amazônia: indo além da "emergência crônica'”. Ipam, 87 p. http://www.ipam.org.br, 2004.

ANDRADE, F. A. Abrindo a discussão de um projeto nacional para a Amazônia. Palestra. Minter/Sudam, 1993, 12 p.

BECKER, B. "Redefinindo a Amazônia: o vetor tecno-ecológico". Em CASTRO, I. E.; GOMES, P. C. C. e CORRÊA, R. L. Brasil: questões atuais da reorganização do território, Bertrand Brasil, 1996, 468 p.

CARDOSO, F. H. e MULlER, G. Amazônia: expansão do capitalismo. São Paulo, Brasiliense, 1977, $205 \mathrm{p}$.

CASTRO e MARIN, R. E. A. “Amazônia Oriental: territorialidade e meio ambiente”. Em Reestruturação do espaço urbano e regional no Brasil. São Paulo, Anpur/ Hucitec, 1993, pp. 121-148.

FBDS/ IBGE/ SAE (coord. SALATI, E. e FERREIRA, A. M. M.). Diagnóstico ambiental, estudos temáticos e sistemas de informações geográficas como subsídio ao Zoneamento Ecológico-Econômico da Amazônia Legal, 1995, relatórios inéditos, 7 vols.

HALL, A. Amazônia: desenvolvimento para quem? Rio de Janeiro, Zahar, 1991, 300 p.

IBASE. A Amazônia legal: politicas de desenvolvimento e seus efeitos econômico-sociais, 1985, mimeo.

IBGE/ SAE (coord. FERREIRA, A. M. M.). Diagnóstico Ambiental da Amazônia Legal, 1995, relatórios e mapas inéditos, 286 p.

INSTITUTO BRASILEIRO DE ANÁLISES SOCIAIS E ECONÔMICAS (Ibase). $A$ Amazônia legal: politicas de desenvolvimento e seus efeitos econômicos-sociais. Rio de Janeiro, 1985, mimeo.

INSTITUTO NACIONAL DE PESQUISAS ESPACIAIS (Inpe) - Programa de Monitoramento por satélite da Amazônia Brasileira, 1997-1998.

KOESTLER, A. Janus: a summing up. London, Hutchington, 1979, 475 p.

MARGULIS, S. Causas do desmatamento da Amazônia brasileira. Brasília, Banco Mundial, 2003, $100 \mathrm{p}$.

MATTOS, M. M. e UHL, C. "Economic and Ecological Perspectives on Ranching in the Eastern Amazon". World Development, 22 (2), 1994, pp. 145-158.

NABUCO, M. R. “A reestruturação industrial e seus efeitos”. Em CARLEAL, L. e NABUCO, M. R. (orgs.). Transformações na divisão Interregional do trabalho no Brasil. Belo Horizonte, Cedeplar/ UFMG, 1989.

SALATI, E.; SANTOS, A. A. e FERREIRA, A. M. M. "Perspectives for Sustainable Management of the Renewable Natural Resources of the Amazon Forest". Academia Bras. de Ciências, no prelo, 49 p.

SANTOS, M. A Natureza do Espaço. São Paulo, Hucitec, 1996, 308 p.

SAWYER, D. R. "Instrumentos de planejamento e gestão ambiental para a Amazônia, cerrado e pantanal. Demandas e propostas, Documento Preliminar". Em PROGRAMA NACIONAL DE MEIO AMBIENTE. PNMA. 1992, mimeo., 51 p. 
THOMAS, K. O homem e o mundo natural. São Paulo, Cia das Letras, 1988.

WEIL, P. A neurose do paraíso perdido. Rio de Janeiro, Espaço e Tempo, 1987, 127 p.

RESUMO - NOS 470 anos iniciais da colonização da Amazônia brasileira, apenas 1\% da área foi desmatada. Porém, nos últimos 35 anos (1970-2005) o desmatamento já atinge $17 \%$ da região e a população aumentou de dois milhões para mais de 20 milhões de habitantes.

Hoje, a colonização da Amazônia brasileira encontra-se em uma fase sem paralelo de expansão na qual os incentivos fiscais passaram a desempenhar um papel secundário, ou seja, o governo como indutor do desenvolvimento foi substituído pela iniciativa privada cujas atividades econômicas tornaram-se lucrativas. As principais forças de transformação são decorrentes de demandas internas do País, especialmente da região centro-sul, bem como do mercado internacional.

As atividades principais responsáveis pela transformação são exploração madeireira, pecuária, produção de grãos, extração mineral, produção de energia hidroelétrica e prospecção de petróleo e energia. Essas atividades foram incentivadas com a implantação de um complexo sistema viário que cruza a Região de Norte a Sul e de Leste a Oeste, substituindo e auxiliando no transporte que antigamente só era feito através dos grandes rios navegáveis.

Palavras-chave: Forças de transformação; colonização; população; desmatamento.

AbSRACT-DURING THE first 470 years of the colonization of the Brazilian Amazon, only $1 \%$ of the area was deforested. In the last 35 years (1970-2005), however, deforestation has already claimed $17 \%$ of the region, whose population increased from two million to over 20 million people.

Today, the colonization of the Brazilian Amazon finds itself in a stage of unparalleled expansion, even if fiscal incentives now play a secondary role. In other words, governmentdriven development has been replaced by private initiatives whose economic activities have become profitable. The main forces of transformation derive from the demands both of the country's domestic markets (especially those in the south and central regions) and of the international marketplace. The main activities responsible for this transformation are logging, cattle raising, grain production, mining, hydroelectric energy production, and oil and energy prospecting. These were invigorated by the implementation of a highway system that now crisscrosses the region from north to south and east to west, replacing or supplementing the navigable rivers used before for transportation.

key-words: Transformation driving forces; colonization; population; deforesration.

Antonia M. M. Ferreira é professora da Faculdade de Geologia da UERJ e diretora de Geociências do IBGE.

Enéas Salati é diretor técnico da Fundação Brasileira para o Desenvolvimento Sustentável (FBDS). @ - salati@fbds.org.br

Trabalho publicado originalmente em SALATI, Enéas et al. Amazônia: um ecossistema em transformação. Manaus/ Brasília, Inpa/Cnpq, 2002, e atualizado para esta publicação.

Texto recebido em 23/2/2005 e aceito em 18/4/2005. 